DOI 10.37882/2223-2982.2021.06.23

\title{
ЛЕКСИЧЕСКИЕ СРЕДСТВА КОМПОЗИЦИОННОЙ ОРГАНИЗАЦИИ КИНОТЕКСТА (НА МАТЕРИАЛЕ СКРИПТОВ ЭКРАНИЗАЦИИ РОМАНА Ф. М. ДОСТОЕВСКОГО «ПРЕСТУПЛЕНИЕ И НАКАЗАНИЕ» НА РУССКОМ И АНГЛИЙСКОМ ЯЗЫКАХ)
}

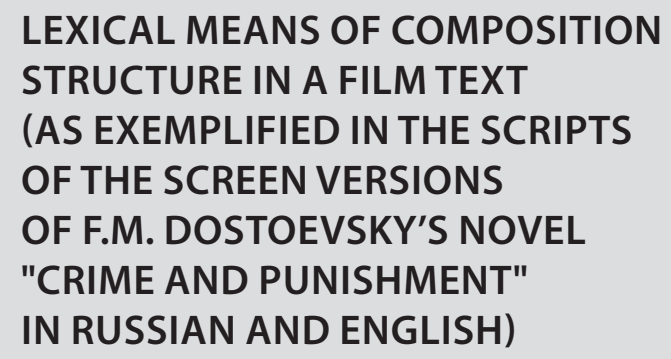

LEXICAL MEANS OF COMPOSITION STRUCTURE IN A FILM TEXT (AS EXEMPLIFIED IN THE SCRIPTS

OF THE SCREEN VERSIONS

OF F.M. DOSTOEVSKY'S NOVEL "CRIME AND PUNISHMENT" IN RUSSIAN AND ENGLISH)

D. Kelesh

Summary: The article deals with the examination of the peculiarities of composition structure in a film text. Special focus is given to examining lexical units used for expressing spatial and temporal relations in the scripts of the screen versions of F.M. Dostoevsky's novel "Crime and Punishment» in Russian and English. The concept of a film text is examined. Types of narration based on spatial, temporal, event-related, and emotional aspects are thoroughly described. Comparative analysis of spatial and temporal lexical units in Russian and English is conducted with the aim to distinguish the tendency in using lexical units in the light of composition structure.

Keywords: composition, film text, spatial, temporal, spatially-temporal relations.

\author{
Келеш Дарья Андреевна \\ Аспирант, Московский государственный областной \\ университет, г. Мытищи \\ solo.dar9294@yandex.ru
}

Аннотация: Статья посвящена исследованию особенностей композиционной организации кинотекста. Особое внимание сосредоточенно на рассмотрении лексических средств выражения локальности и темпоральности в скриптах экранизации романа Ф.М. Достоевского на русском и английском языках. Рассматриваются составляющие понятия «кинотекст». Дается детальное описание видов построения художественного повествования, базирующееся на пространственном, временном, событийном и эмоциональном аспектах. Проводится сопоставительный анализ лексических единиц с пространственным и временным значением на русском и английском языках с целью выявления общих тенденций использования лексем с учетом вида композиционного построения текста.

Ключевые слова: композиция, кинотекст, локальность, темпоральность, пространственно-временные отношения.
И сследование кинотекста не только как произведения киноискусства, но и как коммуникативного целого осуществляли Ю.М. Лотман, Ю.Н. Усов, У. Эко, А.В. Федоров, Ю.Г. Цивьян. На основе характеристик, данных лингвистами, в структуре кинотекста художественного произведения как объекта зрительского восприятия можно выделить следующие составляющие: аудиовизуальные образы, пространственно-временная организация и коммуникативная направленность. Кинотекст представлен двумя составляющими: письменной, включающей в себя титры, надписи как часть интерьера или реквизита; и устной, охватывающей речь персонажей, закадровое повествование, песни, музыкальное сопровождение, мимика и жесты персонажей [8]. При исследовании кинотекста художественного фильма, основанного на тексте литературного произведения, необходимо рассматривать составляющие кинотекста в неразрывном единстве, где каждый элемент несет коммуникативную нагрузку [6, с.4].
Кинотекст, как и художественный, призван выполнять не только коммуникативную, но и эстетическую функцию, и ключевое место при его составлении отводится композиции, предполагающей взаимосвязь элементов текста и их расположение в определенном иерархическом порядке, призванном отразить авторский замысел.

В широком аспекте под композицией понимают совокупность всех отдельных элементов текста. С.Н. Вековищева рассматривает две ключевые композиционные составляющие: интенсивность эмоционального ряда и событийного ряда, - и отмечает, что при событийном развитии происходят также пространственные и временные изменения, в то время как перемена эмоционального состояния может происходить с течением времени. Сюжетное развитие, таким образом, происходит посредством изменения эмоционального и событийного фона [1, c.86]. 
Как мы отметили, составляющей кинотекста является пространственно-временная организация текста и образа, обладающая коммуникативной направленностью. Таким образом, нам необходимо выделить и рассмотреть языковые средства выражения локальности, темпоральности и экспрессивности [9]. Необходимо также отметить, что, как и любое художественное произведение, кинотекст может содержать несколько типов повествования. Рассмотрим несколько видов построения художественного повествования и лингвистические средства организации композиции в кинотексте.

1. Прямолинейное развитие сюжетной линии. В данном случае развитие событийного ряда не влечет за собой изменений эмоционального напряжения. Прямолинейное развитие происходит, например, когда герой рассказывает о пережитых событиях, при этом не происходит пространственных изменений, а эмоциональная насыщенность остается на определенном уровне на протяжении повествования [1, с.88].

2. Обратное развитие сюжетной линии. Читатель узнает об уже свершившемся событии, затем его знакомят с деталями произошедшего. В данном случае время статично, однако возможны пространственные изменения. Так, в скриптах британской экранизации «Преступления и наказания» Ф.М. Достоевского Раскольников рассказывает о том, что произошло в провинции в его отсутствии. Воспоминание о письме матери заставляют испытывать его раздражение, перерастающее в агрессию к жениху сестры, к самому себе из-за собственной беспомощности. В данном случае событийная нагрузка минимальна, из повествования героя мы узнаем, что его сестра собирается замуж для того, чтобы улучшить финансовое положение семьи: «... my sister is pawning herself in marriage for my sake». Герой выражает субъективное отношение к происходящему, использует стилистическиокрашенную лексики: «... get up off their bloody knees», «filthy, bloody city». Событийное развитие не происходит, однако нарастает эмоциональное напряжение героя, одно эмоциональное состояние сменяется другим: раздражения, агрессия, гнев. Пересекаются две временные и две пространственные плоскости: изменение событийного ряда в одной плоскости повлекло изменение эмоционального состояния в другой.

3. Классическое развитие сюжетной линии. В сюжете присутствует завязка, по мере развития событий происходит градуальное изменение эмоционального фона, наивысшая точка эмоционального напряжения, спад напряженности, развязка [10]. Так, в романе завязке предшествует экспозиция, когда читателя знакомят с идей об убийстве. Завязкой служат события, усиливающие эмоциональное состояние главного героя: письмо матери, заставляющее его почувствовать собственную беспомощность из-за неспособности помочь своей семье и оправдать их надежды, встреча Мармеладова, которая заставляет героя еще больше поверить в правильность своих идей; само преступление; последовавшая за ним болезнь; кульминацией можно считать признание Раскольникова в совершении убийства Соне и последующее признание в полицейском участке. В развязке читатель узнает о том, что последовало после суда: жизни Раскольникова на каторге, начале его постепенного исцеления и чувствам к Соне, последовавшей за ним. При классическом развитии сюжета эмоциональная и событийная насыщенность находятся на одном уровне на протяжении повествования.

4. Стремление к эмоциональной напряженности. Целью повествования является достижение наивысшей точки эмоционального фона. Композиция в данном случае выстроена таким образом, что повествование обрывается на моменте эмоционального напряжения, автор оставляет читателя наедине с героями, позволяя ему лишь догадываться, что могло произойти дальше. Это не значит, что в произведении отсутствует развязка. Например, в «Евгении Онегине» повествование заканчивает сценой признания Евгения в любви и отказ Татьяны. Кульминацией является встреча героев в Санкт-Петербурге, осознание Онегиным своих чувств, признание. А развязкой служит эпизод объяснения в любви и ответ Татьяны. В эпилоге «Преступления и наказания» в ровном эмоциональном ряду происходит всплеск, когда Раскольников в порыве чувств падает к ногам Сони. В романе кульминацией стало признание Раскольникова в убийстве, в этот раз напряженным моментом стало его признание в чувствах, которые ему еще не до конца непонятны, и которых он раньше не испытывал. Автор подводит читателя к «кульминации», наращивая интенсивность эмоционального ряда: их холодное общение, его болезнь, недомогание Сони, продолжительная разлука, встреча, все это время героя размышляет о своем отношении к спутнице, определяет, кто она для него, и, наконец, неожиданно для самого себя дает волю своим чувствам.

До момента эмоционального всплеска происходят пространственные и временные изменения, в моменте «кульминации» прекращается перемещение в пространстве, время же устремляется в бесконечность [2, с.89].

5. Кумулятивное начало. В данном случае события аккумулируются в начале повествования, в первой главе или первом абзаце. В каждой части произведения повествуется о прошлом героя, раскрываются его качества, дано видение событий глазами других участников. Каждая сюжетная линия имеет свое композиционное построение, сюжетное развитие, однако все события выстраиваются вокруг ядра, изложенного в начале повествования.

Рассмотрение композиционного построения с уче- 
том эмоционально-событийного ряда дает возможность структурировать художественный текст с замыслом автора, показывая при этом взаимосвязь временных и пространственных параметров.

Временной и пространственный континуумы позволяют читателю испытать чувство движения, перемещения вместе с героями произведения. Погружения реципиента в пространственную плоскость событийного ряда происходит посредством отграничивания одного события от другого, перерывов в развитии, акцентировании внимания на конкретном эпизоде. В кинематографическом произведении пространственное изменение происходит при смене на соответствующий кадр, в художественной литературе для смены локации используется описание, диалоги, размышления героев или автора. Континуум в художественном тексте одновременно непрерывен и дискретен. Будучи непрерывным, он служит для передачи действия, дискретным - качество или состояние [1, с.93].

Поскольку в произведении может быть несколько сюжетных линий, то конституенты временного и пространственного континуумов могут быть расчленены и рассматриваться в рамках событийного ряда конкретной сюжетной линии и ее героев. Они, совершая определенные действия, являются инициаторами изменения временных и пространственных параметров текстового пространства. В каждой сюжетной линии герой погружен в свой пространственно-временной континуум, ограничивающий его в текстовом пространстве, и в то же время все персонажи охвачены одним временным и пространственным промежутком.

Пространственный континуум представлен конкретными, эксплицитными формами выражения в кинотексте. Пространственные отношения в независимости от композиционной организации текста на лексическом уровне выражены языковыми единицами различных частей речи:

1. локальные существительные, включающие категориальную сему пространства. В данную группу вошли: а) топонимы, например, in Petersburg - в Петербург, into the Neva - в воду; б) государственные учреждения, места общественного пользования, police department - участок, at the station - в контору, at the flea market - на Толкучем, to the Haymarket - на перекрестке; в) место жительства, например Bakaleyev's tenement - дом Бакалеева; in Shil's tenement - в доме Шиля; г) части построек, например, to my rooms - приходи; at the house - в доме, in her apartment - у нее; д) внутренний интеpьер, on a sofa - на диване.

Различия в использовании лексических средств локальности обусловлены с одной стороны, недостаточной осведомленностью представителя- ми иного культурного поля о культурных реалиях русскогоговорящего населения, а с другой стороны придать национальный колорит, и исключить потенциальную двусмысленность, как в случае с домами, где располагались главный герой, его родители, старуха-процентщица. Топоним «Neva» знаком иностранному зрителю, так как упоминается в произведениях русской литературы, а город, в котором протекает река, посещается миллионами туристов ежегодно. Толкучий рынок - место, где торгуют подержанными вещами [7]. Данное понятие может быть незнакомо современными российскому читателю, так как данная реалия культурная жизни постепенно исчезает, описательное выражение «flea market» позволяет донести смысл до англоговорящего зрителя.

2. предложные группы с существительными, не денотирующими конкретный объект, например, on a cliff - у вершины скалы, и указывающими на определенный объект, который упоминался ранее. В следующем предложении сообщается, где один из персонажей должен был находиться: «l thought I told you to stay upstairs». - Я же просил вас постоять. В следующем предложении лексема была заменена на существительное с обобщенным значением места: «l just wanted to keep an eye on the place». Как мы видим, для обозначения лексем, которые не денотируют конкретный объект, включенный в область пространственной активности персонажа, используются слова с обобщенным значением, употребленные с неопределённым артиклем.

3. местоименные наречия, например, «уou stay here» - оставайтесь вы здесь, «I'm going to spend the night here with yоu». - Я ночую здесь.

4. указательные местоимения, например, «down those stairs» - с лестницы; «this way» - сюда.

5. пространственные предлоги, например, «get out» - вон, «l shall never come back». - Я уже не ворочусь; «just up the street» - по улице.

6. фигура речи с пространственным значением. В данном случае значение лексемы метафорично, и не может использоваться для соотнесения с конкретной точной пространственной плоскости произведения. Например, в предложении «Oh, some rabbit hutch» герой образно называет место жительства кроличьей клеткой; в идиоме «hе hides his light under a bushel» речь идет о сокрытии своего таланта.

Лексемы с пространственным значением могут выполнять атрибутивную функцию в предложении, например, «scourge of Petersburg's criminal classes» - здешний пристав следственных дел. В советской экранизации использование относительного прилагательного «здешний» предполагает, что зритель, уже знакомый с творче- 
ством писателя, помнит место действия, в британских скриптах название города упоминается еще раз, в первый раз город упоминался как место приезда сестры главного героя, однако о том, что действие разворачивается в этом городе, не упоминалось ранее.

В рассмотренных случаях лексические средства, используемые в британских скриптах, были призваны облегчить восприятие текста англоговорящим носителем. Лексемы с пространственным значением были использованы в скриптах преимущественно при описании героями прошедших событий и при сообщении будущих интенций. Таким образом, использование локальных лексических единиц наиболее востребовано при прямолинейном и обратном развитие сюжетной линии.

В языке для обозначения объективных интервалов времени существуют специальные единицы. К ним относят месяцы, сезоны, обозначения точного времени и другие обстоятельства времени. Эти временные показатели имеют абсолютное значение и являются, как отмечают некоторые исследователи, автосемантичными [3, с.67].

Синсемантические обстоятельства имеют относительное значения, то есть они используются для обозначения времени относительно конкретной точки временной плоскости и не могут быть актуализированы вне ее $[1$, c.72].

Временные показатели используются для выражения предшествования, следования, одновременности, прерывности и включают в себя:

1. временные наречия, например, «soon» - на днях, "yesterday» - со вчерашнего; "come to my rooms tomorrow at 7» - приходи завтра часу в седьмом, «then»- потом.

2. местоименные наречия, которые необходимо рассматривать в контексте, например, when, while.

3. предлоги, выражающие временные отношения. Временное значение в предлогах может быть выражено опосредованно и непосредственно. В первом случае временное отношение выражается посредством сочетания предлога и момента времени совершения действия, например, «l haven't seen you for three years». - Неужели я не посмотрю на тебя после трех лет. При непосредственном выражении предлог сочетается с единицами времени. Большинство предлогов могут передавать временное значение как опосредовано, так и непосредственно.

В кинотексте, включающем невербальные средства коммуникации, часто можно наблюдать изменение хода течения реального времени. Например, сцена, когда главный герой слышит диалог Лизаветы на улице, и узнает, что на следующий день ее не будет дома в семь часов.
В скриптах советской экранизации герой воспроизводит в голове последнюю услышанную фразу, голос женщины повторяет десять раз время предстоящей встречи, таким образом, что временной поток замедляется, происходит частичная остановка течения времени. Внимание зрителя заостряют на ключевом моменте, когда герой окончательно решил совершить убийство.

В британской экранизации растяжение временного континуума наблюдается, когда герой идет на убийство. После слов Настасьи «It's gone 7» указаны фразы «bell tolling», «screaming», «man laughing». В романе открываются мысли главного героя: собираясь на убийство, он думает о том, что видит по пути к дому жертвы, размышляет об устройстве фонтана, маленький мальчик играет с палкой, которая при ударе об забор издает звук похожий на тиканье часов и словно отчитывает последние секунды свободной жизни.

В романе большое значение отводится временным рамкам, в которые заключены герои, ключевым эпизодом является чтение главы о воскрешении Лазаря, сцена происходит на четвертый день после убийства старухи: «Lord, he has been dead four days» - ...ибо четыре дни, как он во гробе. В советской экранизации эпизод чтения Евангелие отсутствует.

В английских скриптах числительные, описывающие даты и время, употребляются чаще для формирования более четкой временной линии. Рассмотрим пример: "The decorators were there on the day of murder itself. He was there the day before». - Красильщики мазали в день убийства, а он за три дня там был? В скриптах советской экранизации герой уточняет, был ли его друг на месте преступления три дня назад, в то время как в английском варианте он утвердительно указывает на то, что товарищ посетил жертву за день до ее убийства [5, с.505]. В первом варианте использована фраза из оригинального романа, где автор подчеркнул, что с момента убийства прошло три дня, таким образом, читателю легче будет проследить, что чтение Библии произошло на четвертый день.

Временные показатели, так же, как и пространственные, используются при обратном, прямолинейной повествовании, когда герои описывают произошедшие с ними события или для ссылки на будущие планы.

Кинотекст, являясь разновидностью художественного текста, включает в себя пространственную, временную составляющую, слуховые и зрительные образы и обладает коммуникативной направленностью. В кинотексте могут сочетаться разные виды организации художественной композиции: прямолинейное развитие сюжетной линии, когда герой рассказывает о пережитых событиях, при этом не происходит пространственных изменений, 
также не меняет эмоциональный фон; обратное развитие сюжетной линии, когда изначально известно о событии, и затем читателя знакомят с деталями произошедшего, классическое развитие сюжетной линии, при котором события разворачивается постепенно и последовательно, кумулятивное начало, когда события упоминаются в начале повествования и в дальнейшем раскрывается прошлое героя. Поскольку в кинотексте речевая деятельность представлена преимущественно в диалоговой форме, в нем четко выражены пространственно-временные отношения. Лексические единицы с пространственным значением представлены: локальными существитель- ными, включающие категориальную сему пространства; предложными группами с существительными, которые денотируют или не денотируют конкретный объект; местоименные наречия, указательные местоимения; пространственные предлоги. Лексемы с временным значением могут быть выражены временными наречиями, местоименными наречиями, предлогами, выражающими временные отношения. Пространственные и временные показатели часто используются при обратном, прямолинейной повествовании в кинотексте, когда герои описывают произошедшие с ними события или при классическом развитии для выражения намерения.

\section{ЛИТЕРАТУРА}

1. Вековищева С.Н. Взаимообусловленность и взаимозависимость категорий пространства и времени в художественном тексте на материале английского и русского языков в сопоставительно-переводческом аспекте: дисс. к. филол. наук, 2000. 171 с.

2. Винокур Г.О. Филологические исследования: Лингвистика и поэтика. М.: Наука, 1990. 452 с.

3. Гулыга Е.В., Шендельс Е.И. Грамматико-лексические поля в современном немецком языке. М.: Просвещение. 1969. 184 с.

4. Достоевский Ф.М. Преступление и наказание. Том 6. Л.: Наука, 1973. 426 с.

5. Мюллер М. Англо-русский словарь. М: Советская энциклопедия, 1969. 912 с.

6. Слышкин Г.Г., Ефремова М.А. Кинотекст (опыт лингвокультурологического анализа). М.: Водолей Publishers, 2004. 153 c.

7. Фундаментальная электронная библиотека «Русская литература и фольклор» (ФЭБ) http://feb-web.ru/feb/ushakov/ush-abc/default.asp (дата обращения: 25.03.2021).

8. Швейцер А.Д. Перевод и лингвистика. 0 газетно-информационном и военно-публицистическом переводе. М.: Воениздат, 1973.280 с.

9. Cinematext.ru. URL:http://cinematext.ru/movie/prestuplenie-i-nakazanie-1969/ (дата обращения: 25.03.2021).

10. Scripts.com. URL: https://www.scripts.com/script/crime_and_punishment_6053 (дата обращения: 25.03.2021).

(c) Келеш Дарья Андреевна (solo.dar9294@yandex.ru). 